\title{
Knock Behavior of SI-Engines: Thermodynamic Analysis of Knock Onset Locations and Knock Intensities
}

\author{
M. Rothe, T. Heidenreich and U. Spicher \\ Institut fuer Kolbenmaschinen, Universitaet Karlsruhe (TH), Germany
}

\author{
A. Schubert \\ Institut fuer Technische Thermodynamik, Universitaet Karlsruhe (TH), Germany
}

Copyright $\odot 2005$ SAE International

\begin{abstract}
A general definition and an index for the assessment of different engine knock behavior have been developed. The knock onset locations have been determined by piezoresistive pressure actuators and optical fiber probes in full load engine operation mode. The thermodynamic conditions at the knock onset locations have been quantified by CFD-calculations. Therefore the local fuel concentration, mixture temperature and residual gas concentration have been considered. These calculated thermodynamic conditions were further used to calculate the necessary volume of an exothermal center for the generation of the maximal measured pressure amplitudes.
\end{abstract}

\section{INTRODUCTION}

Knock in gasoline engines is one of the major challenges to achieve higher thermal efficiencies. The need to improve thermal efficiency and the application of knock control systems increase the demand to calibrate engines closer to the allowable knock limit with consequential reductions in safety limits. Today's combustion engines show a specific knock behavior at high speeds. The phenomenon is characterized by excessively high pressure amplitudes with stochastic occurrence. Thereby the knock intensity close to the knock limit does not increase proportionally by advancing ignition timing. Rather the pressure amplitudes at the knock limit of individual cycles increase up to a multiple of ordinary knock amplitudes. The phenomenon occurs independent of the mixture formation process in both natural aspirated and turbo charged engines as well as in engines with direct injection and port fuel injection. Therefore, this phenomenon is a fundamental issue of modern SI engines.

\section{BACKGROUND}

Extensive experimental and numerical [1,2] investigations have been done to clarify the nature of the phenomenon of knocking combustion. Knocking combustion is almost always a result of auto-ignition processes in the end gas ahead of the normal flame front. Because auto-ignition centers are usually very close to the combustion chamber walls, these autoignition processes are not influenced by the flame front due to their spatial separation [3]. Inhomogeneous charge composition and temperature distribution resulting from different heat capacities of fuel, exhaust gas and fresh air in the end gas effects the location of auto-ignition centers. The temperature distribution in the end gas is the decisive factor in determining the chemical reactions. From this point of view, auto-ignition starts locally at so called "hot-spots" [5] in the end gas, which have a higher temperature in comparison to the surrounding area. The behavior of that hot spot depends on one hand on thermodynamic state variables, like pressure, temperature and air-fuel ratio and on the other hand on the temperature gradient relative to the surrounding end gas [1]. After auto-ignition the resulting knock amplitude depends on the chemical reaction rate [12]. If, hence, the chemical reaction rate within the auto ignition volume is fast enough $(<10 \mu \mathrm{s}$ [7]) a pressure compensation into the surrounding area is not possible. This causes pressure and dilution waves which move with sonic speed into the ambient unburned mixture and, again, lead to a decrease of the auto-ignition delay there $[6,7]$. This can lead to further auto-ignitions in the unburned gas mixture, which can cause a developing detonation under certain conditions [9]. The cylinder walls reflect the generated pressure waves, which results in complex pressure wave profiles in the combustion chamber [12]. The volumetric energy release rate is represented by the excitation time and according to $[6,7,8]$ the decisive factor for the generation of a pressure wave. The maximum value of the excitation time for the formation of a knock amplitude is about $10 \mu \mathrm{s}$, whereas this value is pressure, temperature and air-fuel ratio dependent [12]. For real end gas temperatures between $800 \mathrm{~K}$ and $1400 \mathrm{~K}$ and cylinder pressures up to 50 bar, the formation of knock amplitudes is likely only for stoichiometric mixtures. For air-fuel ratios $\lambda>2$ the probability of local pressure formation is low and for air-fuel ratios $\lambda>3$ nearly impossible. The chemical reaction rate is thereby more pressure dependent than temperature dependent [12]. 


\section{KNOCK BEHAVIOR AND CONCEPTUAL FORMULATION}

The knock phenomenon to be investigated is characterized by excessively high pressure amplitudes nearby or direct at the knock limit. Due to this damaging knocking cycles, an efficient engine operation at the knock limit is impossible, due to the risk of severe engine damage. To characterize the knock behavior of an SIengine with wide open throttle (WOT) the control range (CR) of a knock control system will subsequently be introduced as an index. The $\mathrm{CR}$ is defined as the advance ignition angle between the knock limit $(K L)$ and the damage limit (DL) of a specific engine operation point

$C R=\alpha_{i, D L}-\alpha_{i, K L}$

with the ignition angle $\alpha_{i}$ at $\mathrm{KL}$ and the ignition angle $\alpha_{1}$ at $\mathrm{DL}$. A large CR, which is a significant distance between $\mathrm{KL}$ and $\mathrm{DL}$, characterizes a controllable knock behavior $(\mathrm{CKB})$. For low - or negative - values of $\mathrm{CR}$, an engine operation at $K L$ with a safe distance to $D L$ is critical and extreme knock behavior (EKB) is evident.

One major problem calculating the CR is the absence of universal definitions for $\mathrm{KL}$ and $\mathrm{DL}$. These quantities are subjected to manufacturer, engine and operating point specific definitions. Within these investigations the definitions for $\mathrm{KL}$ and $\mathrm{DL}$ were chosen as follows:

$$
\begin{aligned}
& \text { KL } 1 \% \text { cycles with } \mathrm{KA}>4 \text { bar } \\
& \text { DL } \quad 1 \% \text { cycles with } \mathrm{KA}>20 \text { bar, }
\end{aligned}
$$

with the knock amplitude $\mathrm{KA}$, which is defined as the maximal zero-to-peak pressure of the high-pass filtered cylinder pressure. Since the calculation of this values is based on measured pressure curves, an appropriate pressure sensor as well as an appropriate adaptation to the combustion chamber is of significant importance. For all subsequent illustrated investigations, only the signals of the reference pressure sensor (see next chapter) were utilized. The database for each ignition angle is totaled to 3000 consecutive cycles.

Figures 1 and 2 present the engine knock behavior in different operating points. Both, at $3000 \mathrm{rpm}$ WOT and $5000 \mathrm{rpm}$ WOT damaging knock amplitudes (KA > 20 bar) can be provoked by adequate ignition angles.

The ignition angle difference between $\mathrm{KL}$ and $\mathrm{DL}, \mathrm{CR}$ respectively, for $3000 \mathrm{rpm}$ (figure 1) is $4.3 \mathrm{CAD}$. This CR is sufficient to operate the engine at $\mathrm{KL}$ with a safe distance to $\mathrm{DL}$, that is $\mathrm{CKB}$ for the operating point with 3000 rpm WOT.

The ascertained $\mathrm{CR}$ for the operating point with $5000 \mathrm{rpm}$ WOT (figure 2) is $1.7 \mathrm{CAD}$. Although no damaging knock amplitudes (KA > 20 bar) of the 3000 consecutive cycles were detected at $\mathrm{KL}$, a safe engine operation at $\mathrm{KL}$ can not be guaranteed because of the small $\mathrm{CR}$, which is related to $\mathrm{EKB}$ in the engine operating point with 5000 rpm WOT.

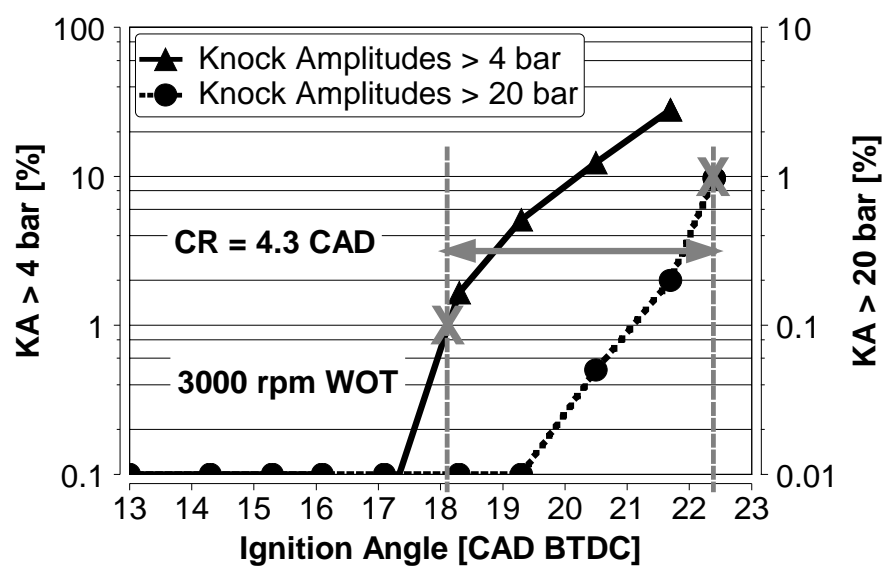

Figure 1: 3000 rpm; control range approx. 4.3 CAD; controllable knock behavior (CKB).

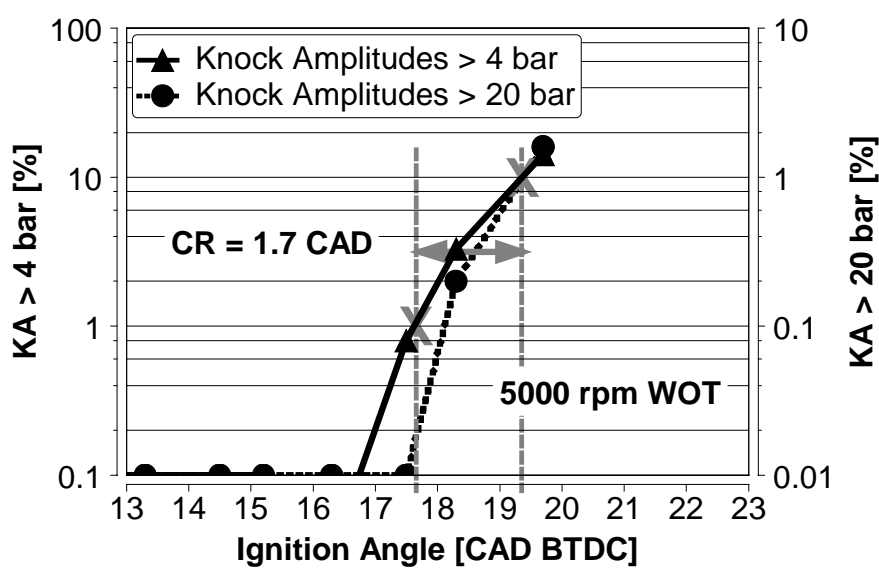

Figure 2: 5000 rpm; control range approx. 1.7 CAD; extreme knock behavior (EKB).

For the following investigation of the engine knock behavior the operating point at $3000 \mathrm{rpm}$ WOT will be the reference for $\mathrm{CKB}$ and the operating point at 5000 rpm WOT will be the reference for EKB.

\section{ENGINE, TEST BED AND INSTRUMENTATION}

A 4-cylinder production engine with 2.2 I displacement and intake stroke direct injection was utilized for the investigations. Each cylinder has 4 valves, with one filling port and one swirl port. The filling port is equipped with a swirl flap. For low engine speeds the swirl flap is closed and the in-cylinder swirl intensity is increased. For higher engine speeds the swirl flap is stepless opened, the cylinder charge mass increases and the swirl decreases. Further technical engine data are listed in table 1. Due to a good access for the measurement probes cylinder 2 was chosen as reference. A schematic of cylinder 2 in horizontal projection is given in figure 3 . Inlet (IV) and 
exhaust valves (EV) are indicated as well as the filling port with the swirl flap.

\begin{tabular}{|c|c|c|}
\hline Max. Power & $\mathrm{kW}$ & 113 \\
\hline Max. Torque & $\mathrm{Nm}$ & 216 \\
\hline Compression ratio & - & $12: 1$ \\
\hline Bore & $\mathrm{mm}$ & 86.0 \\
\hline Stroke & $\mathrm{mm}$ & 94.6 \\
\hline Valves / Cylinder & - & 4 \\
\hline Spark Plug & - & central \\
\hline
\end{tabular}

Table 1: Technical Data of test engine.

The installation positions of the 9 single optical fiber probes in the cylinder head as well as the 8 optical fiber probes in the optical spark plug are shown in the figure. Furthermore the position of the 5 pressure sensors adapted to the combustion chamber is indicated.

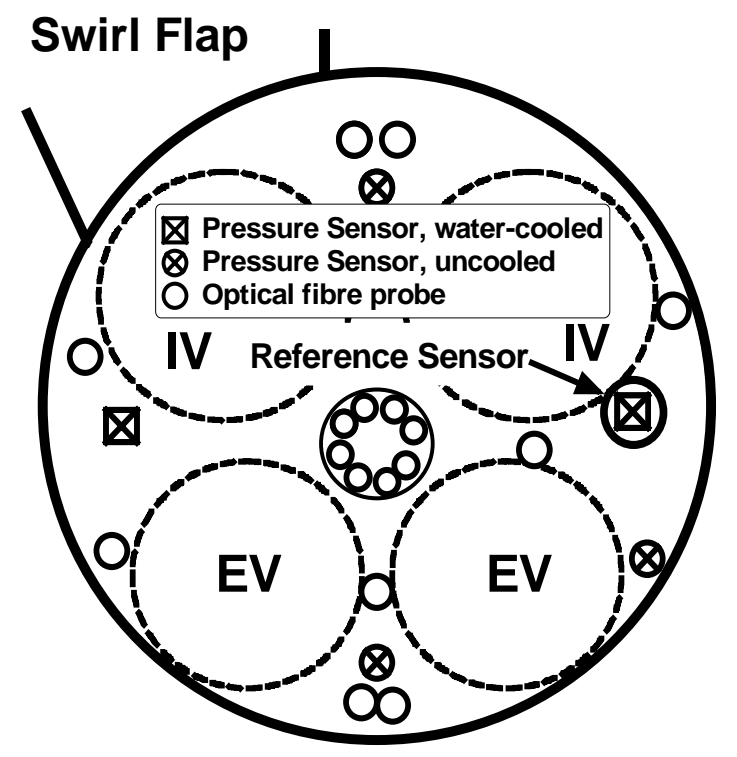

Figure 3: Schematic of cylinder 2; positions of swirl flap, pressure sensors and optical fiber probes.

Two of the sensors are water-cooled Kistler 6061 and the others uncooled Kistler 6053. The rimmed sensor (6061, water-cooled) was used as the reference sensor. Both 6061 sensors are flush mounted to the chamber roof via sleeves. The uncooled 6053 were mounted according to Kistler instructions front tightening via prechamber outlet of the dimensions $3.0 \mathrm{~mm} \times 2.5 \mathrm{~mm}$. In addition to the cylinder indication two low pressure sensors were mounted in the inlet port (Kistler 4075) and the exhaust port (Kistler 4045). An adapter was utilized on one hand for the adaptation of the sensor to the exhaust port and for the protection of high exhaust gas temperatures on the other hand. The measured low pressure signal curves were further used as boundary conditions for the flow simulations. The signals of all pressure sensors are digitized in 0.1 CAD, processed in electrical amplifiers (Kistler) and recorded together with the data of a lambda sensor (cylinder 2) and the ignition point in the data acquisition system Smetec Combi Pro.

\section{NUMERICAL MODELS}

Based on various simulation models thermodynamic state variables and their transient behavior during the cycle up to the time of auto-ignition will be analyzed and further be assessed in their relevance to engine knock behavior. These state variables both result from $0 \mathrm{D}$ heat release analysis (BREMO) and from 3D-flow simulation (CFD). The dependency of the measured knock amplitudes and the calculated local and global state variables is analyzed within another $0 \mathrm{D}$-calculation (HOMREA), in which the resulting chemical reaction rate represents the cause variable for the physical formation of local pressure peaks (knock amplitudes).

\section{HEAT RELEASE ANALYSIS (BREMO)}

The temperature development in the end gas of SIengines can be calculated by measured pressure curves, fuel mass, air-fuel ratio $(\lambda)$, inlet and outlet temperatures, wall heat losses and the motored cylinder pressure curve. The calculated temperature of the end gas and the measured cylinder pressure at time of knock onset respectively are state variables for the calculation of the auto ignition. Further state variables are the local air-fuel ratio in the knock onset region and the involved volume during the auto ignition. Both are calculated within the CFD simulation.

\section{COMPUTATIONAL FLUID DYNAMICS (CFD)}

Based on CAD data of the piston, the combustion chamber and the inlet and exhaust ports and the valve lift curves, a computational grid of the reference cylinder 2 was modeled, as seen in figure 4.

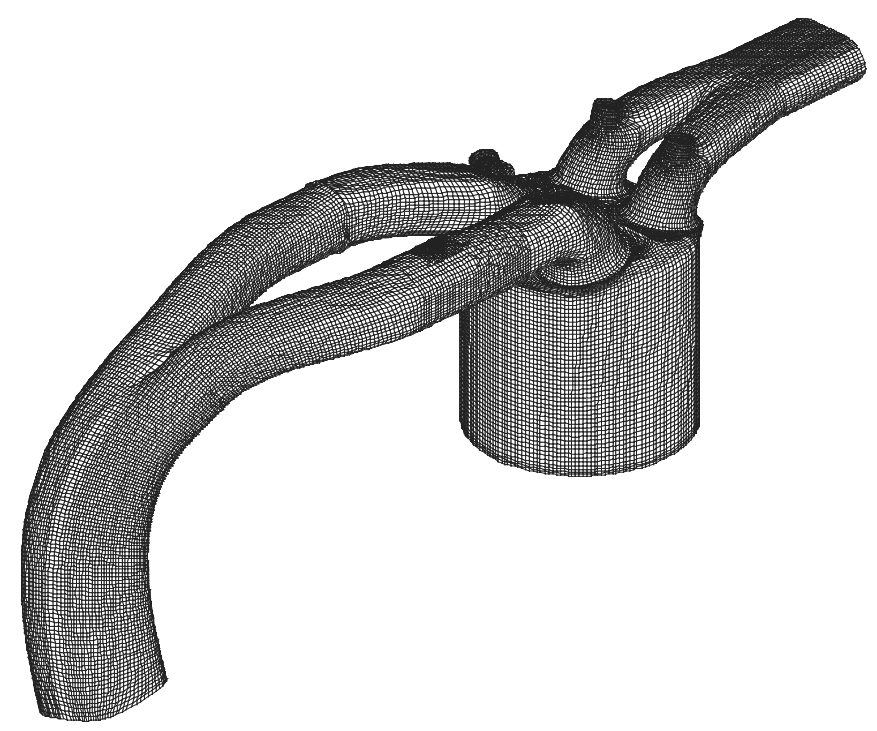

Figure 4: Computational grid of the reference cylinder 2; combustion chamber, inlet and outlet ports. 
The positions of the low pressure sensors at the inlet and exhaust port represent the model boundaries at which the measured state variables $(T, p)$ are handed in the model. The simulations starts at 130 CAD ATDC before the exhaust valve opens and is calculated for 720 CAD. An injection model was adjusted to experimentally determined injection patterns, so that the injection of the gasoline in the cylinder can also be considered. Furthermore a combustion process based on an extended Weller model $[14,15]$ was utilized for the simulation. The initialization of the cylinder pressure and the inlet and outlet temperatures at the beginning of the calculation are based on measured data. The initialization of the cylinder temperature was calculated within BREMO. The injection time as well as the start of injection were ascertained from the application software, the injection mass calculated from the measured fuel consumption. Preliminary fuel and exhaust gas mass in the inlet port is taken into account by two cycle computations. The simulation results will be used to determine the volume of the auto-ignition center in the end gas as well as for the determination of the local airfuel mixture of the auto-ignition center in the end gas. Furthermore the calculated end gas area should be validated on the measured propagation of the primary flame front by the optical fiber probes.

\section{HOMOGENEOUS REACTIONS (HOMREA)}

The program is designed to simulate spatially homogeneous systems, like ignition in shock tubes, in Homogeneous Charge Compression Ignited $(\mathrm{HCCl})$ engines, in rapid compression machines or in the endgas of SI-engines. Options include calculation of isothermal or adiabatic systems, or systems with a specified temperature history. Furthermore global heat losses by blow-by can be taken into account.

The end gas of an SI-engine can be modeled as an autoignition center in a combustible mixture. The model considers a small homogenous mass of reacting mixture that is surrounded by an inert mixture with the same conditions. The model combines energy and species equations for the reacting mixture with a gas dynamic constraint for the expansion of the exploding center. The underlying differential equations of the model, which describe the complex chemical and dynamic gas behavior of an auto-ignition center zero dimensional are like follows [12]:

\section{- Energy conservation}

$\frac{\partial T}{\partial t}=\frac{1}{\bar{C}_{p}-\Re} *[\underbrace{\frac{1}{c} \sum_{i=1}^{n s} \dot{w}_{i} *\left(\Re T-\bar{h}_{i}\right)}_{\text {heat }}-\underbrace{\Re T\left(\frac{1}{V} \frac{\partial V}{\partial t}\right)}_{\text {work }}]$

\section{- Species conservation}

$$
\frac{\partial V}{\partial t}=\dot{w}_{i}-c_{i}\left(\frac{1}{V} \frac{\partial V}{\partial t}\right)
$$

- Temporal variation of the auto-ignition volume

$$
\frac{d V}{d t}=\frac{\alpha V}{r} \frac{d r}{d t}
$$

whereas parameter $\alpha$ identifies a planar, cylindrical or spherical geometry (value 1,2 or 3 ). Under the presumption of an isentropic state change [12] the temporal change of the volume of the kernel radius occurs as a function of the pressure within the exothermal center as follows:

$$
\frac{d r}{d t}=\frac{2 \alpha_{0}}{\kappa-1}\left[\left(\frac{p}{p_{0}}\right)^{\frac{\kappa-1}{2 \kappa}}-1\right]
$$

The definitions of the variables used in the preceded formulas are given in the 'Definitions' section at the end of the paper. Characteristic values for the characterization of the dynamic behavior of an exothermal center are the ignition delay $\tau$ (defined in this model as the time in which $5 \%$ of the chemical heat is released) and the chemical reaction rate $t_{e}$ (time between ignition delay and maximal heat release). A further parameter is the maximum pressure pulse, which can be regarded as the amplitude of the resulting pressure wave.

Figure 5 shows the dynamic behavior of an exothermal center within a stoichiometric iso-octane / air mixture.

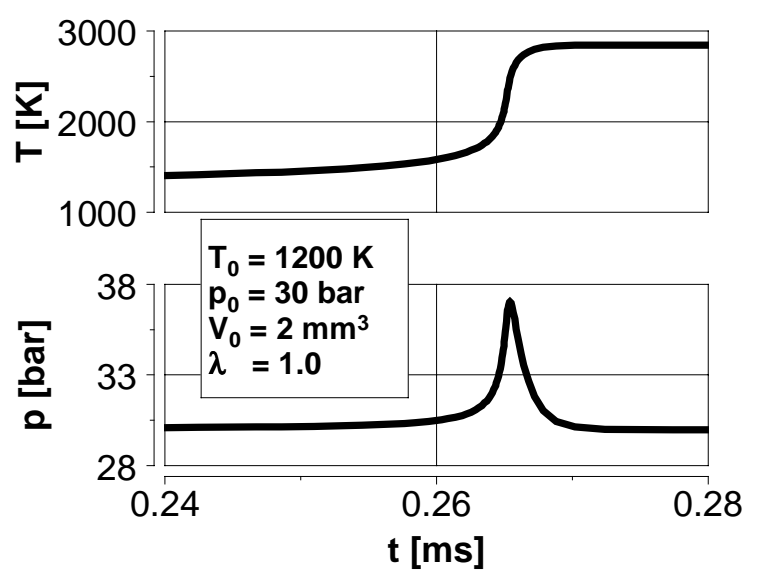

Figure 5: Dynamic behavior of an exothermal center within an stoichiometric iso-octane / air mixture.

The temperature development can be seen at the top, whereas the time of auto-ignition can be identified by the temperature increase after approximately $0.265 \mathrm{~ms}$. The exothermal heat release warms up the gaseous mixture within the auto-ignition center on one hand, and performs expansion work at the surrounding mixture on the other. The pressure of the exothermal center rises during autoignition, but attenuates as a result of the subsequent expansion phase. The maximal pressure amplitude depends therewith on the chemical reaction rate and the gas dynamic expansion of the exothermal center, whereas the latter is limited by the sonic speed in the surrounding mixture. 


\section{RESULTS}

The investigation of the different knock behaviors of the test engine were generally separated in experimental and numerical parts. Within the experimental part the cyclic variations and their dependence on the knock behavior were investigated. The results further allow the verification of the simulation results. Numerical models are utilized for the investigation and the assessment of the mean thermodynamic state variables and their dependence with the knock behavior.

\section{EXPERIMENTAL WORK}

The experimental investigations are separated in the detection of the knock onset locations on one hand and the determination of the propagation of the primary flame front and the knocking reaction front on the other. The main focus is put on the reproducibility of the knock onset locations and the corresponding end gas.

\section{Detected knock locations}

Based on the measured pressure curves of the 5 sensors applied to reference cylinder 2, the times of the knock onsets were determined for each sensor. Based on these times and the dependent sensor positions in the combustion chamber, the knock onset locations have been calculated within a mathematical routine. This routine basically consists of 8 given vectors of plausible knock onset times and related positions (such like fuzzy rules) and the resulting knock positions. Based on the 5 times of knock onset and these 8 rules, the knock onset location could be determined within a 45 degree circle segment.

Figure 6 shows the detected knock onset positions for both reference operation points. Cylinder 2 is schematically presented, with the inlet and outlet valves and the swirl flap (see also figure 3). Further the circle segments marked by the positions 1-8 are shown. For each reference point the major zone of knock onsets for $\mathrm{KA}>4 \mathrm{bar}$, the major zone of knock onsets for $K A>20$ bar and further the zone with the fewest detected knock onsets are marked. 3000 consecutive cycles at $\mathrm{DL}$ are the underlying data basis for each reference point, where 872 knock onsets for the operating point with CKB and 287 knock onsets for the operating point with EKB were detected.

At 3000 rpm with CKB most of the KA > 4 bar were found at the swirl inlet port, at the cooler cylinder section of the inlet valves respectively. The knock onset locations for cycles with $\mathrm{KA}>20$ bar were mostly detected near the exhaust valve, also on the side of the swirl port. The knock onset zones for KA > 4 bar and KA > 20 bar are different respectively. The fewest knock onsets in this operating mode were detected near the left exhaust valve, at the side of the hotter exhaust valves.
At 5000 rpm with EKB the knock onset locations for $K A>4$ bar and for $K A>20$ bar were detected at the inlet port with the swirl flap, at the cooler cylinder section with the inlet valves. The knock onset behavior for various knock amplitudes is different for the investigated operation modes. The fewest knock onsets were detected behind the hot exhaust valves.

\section{$3000 \mathrm{rpm}$}

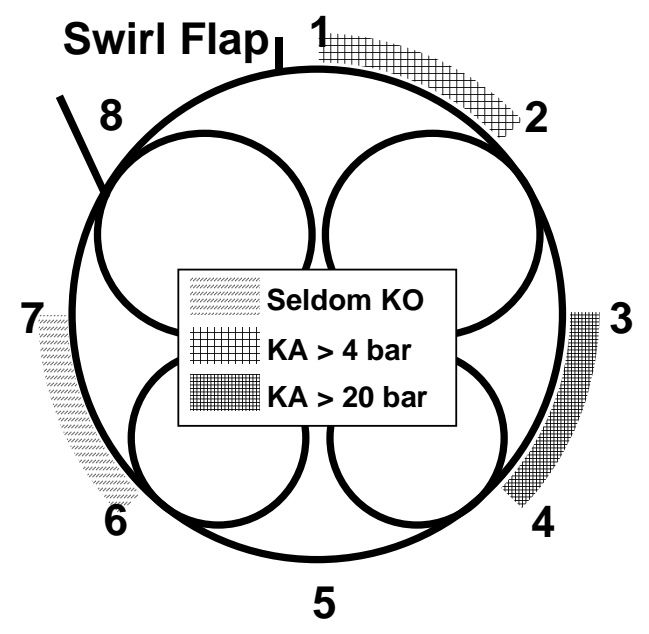

5000 rpm

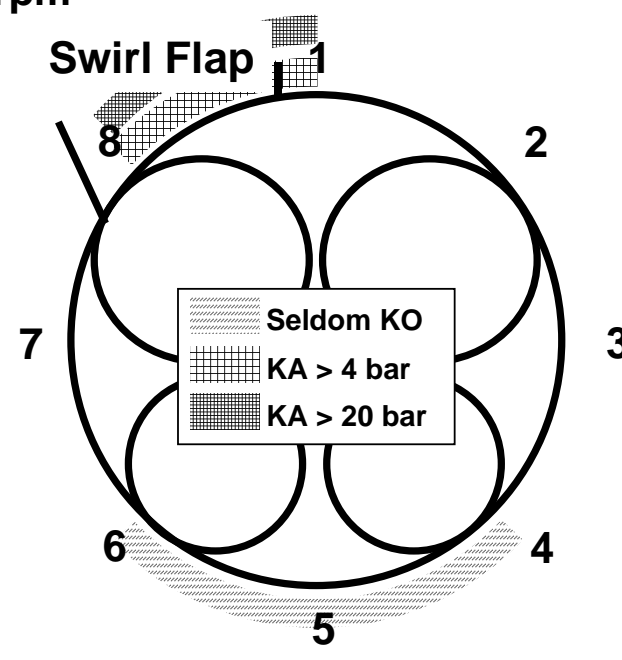

Figure 6: Detected knock onset locations for 3000 rpm (top) and $5000 \mathrm{rpm}$ (bottom).

These results lead to the assumption, that the knock onsets are primary not wall temperature dependent. Furthermore the detected knock onsets for KA $>20$ bar is in $95 \%$ of all cases reproducibly at the presented locations. This coherence leads to the assumption, that the formation of $K A>20$ bar either depends on characteristic cyclic variations of the primary flame front or depends on an operating point specific characteristic of the thermodynamic state variables. The investigation of $K A>20$ bar and the propagation of the primary flame front will be discussed in the next section. 


\section{Primary flame front and knocking reaction front}

The local light intensity during the combustion was measured via 17 adapted optical fiber probes, see figure 3. These optical fiber probes initially detect the passing primary flame front as a signal change (increasing light intensity). In case of a knocking cycle, the passing knocking reaction front can be detected as a further signal increase followed by typical signal waves of high frequency [10]. Based on the propagation of the measured primary flame front and the knocking reaction front, the different knock behavior of the reference operating points will be compared. Figures 7 and 8 show typical examples of cycles with KA $>20$ bar. For each operating point the primary flame propagation based on signals of the optical fiber probes (top) and the passing knocking reaction front (bottom) detected by optical fiber probes (solid line) and by pressure sensors (dashed line) are given. Furthermore the calculated propagation speeds for both, the flame front and the knocking reaction front are shown. The isolines represent the fronts at the given CAD.

\section{0 rpm}
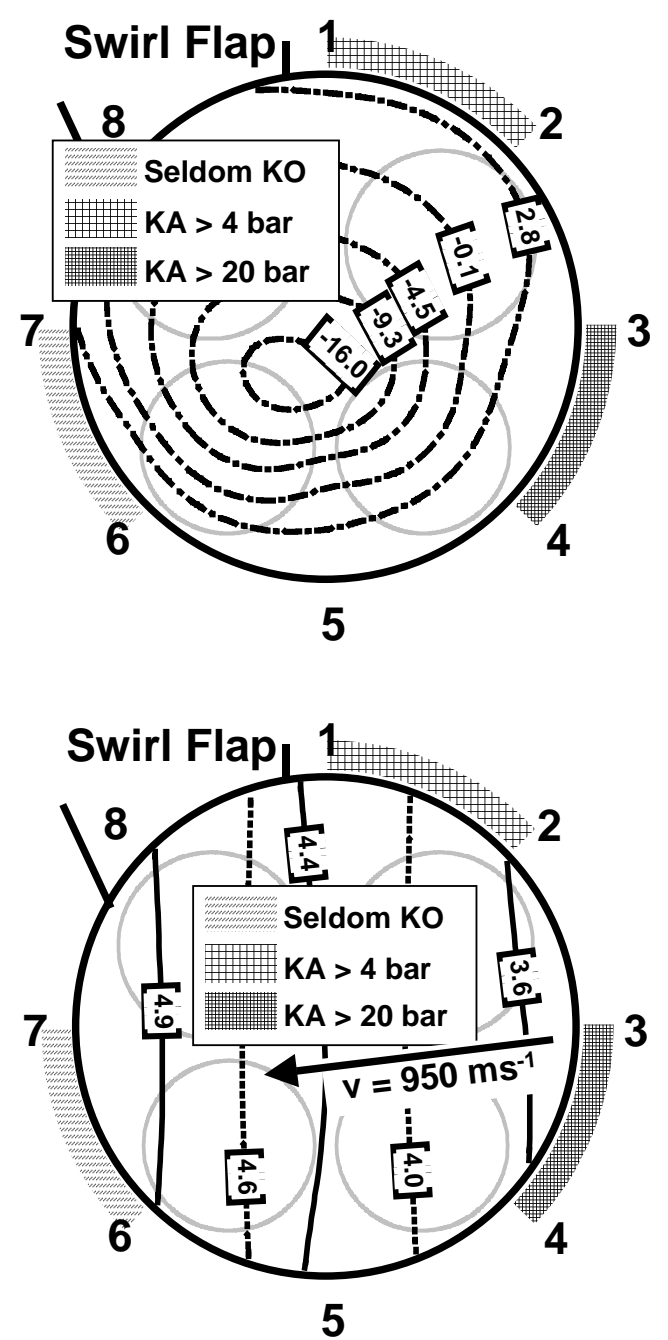

Figure 7: Typical propagation of flame front (top) and knocking reaction front (bottom) for $3000 \mathrm{rpm}$ for a knocking combustion with 23 bar amplitude.
Figure 7 presents a cycle with 23 bar knock amplitude for the reference point at $3000 \mathrm{rpm}$ with CKB. Due to higher swirl the propagation of the flame front is not evenly spread in all directions. The end gas is located between the right inlet valve and the right exhaust valve. The detected major onset location for KA > 20 bar therewith results in the end gas region. The propagation of the knocking reaction front, both detected on the signals of the optical fiber probes and the signals of the pressure sensors confirm the automatically calculated knock onset locations. Independent of the measured signals utilized, knocking reaction front speeds of approx. $950 \mathrm{~ms}^{-1}$ were determined, which corresponds to the sonic speed. Figure 8 presents a cycle with 28 bar knock amplitude for the reference point with $E K B$. Like in the operating point with $\mathrm{CKB}$ the detected propagation of the primary flame front is not evenly spread in all directions. In this case the end gas region is located in the region of the left inlet valve, the region, where most knock onsets have been detected.
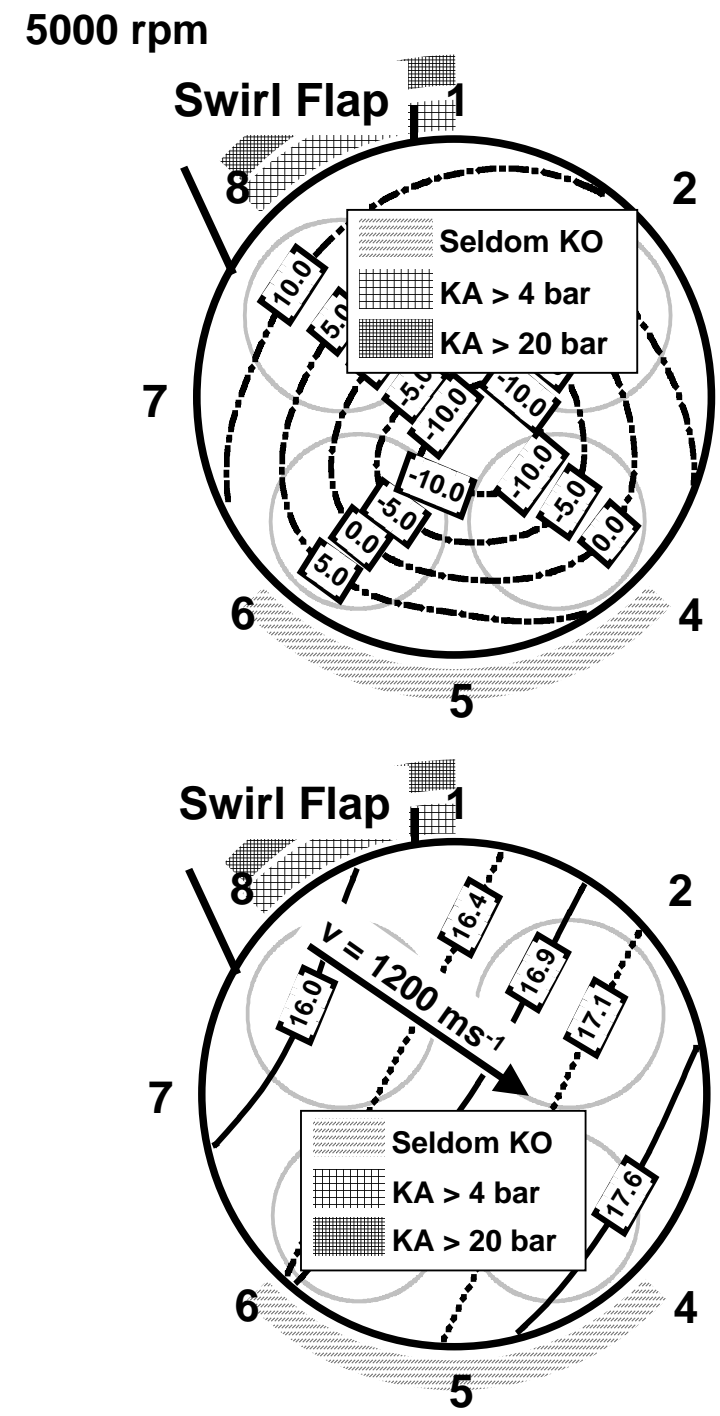

Figure 8: Typical propagation of flame front (top) and knocking reaction front (bottom) for $5000 \mathrm{rpm}$ for a knocking combustion with 28 bar amplitude. 
The knocking reaction front determined confirms the automatically calculated knock onset location also for this operating point with EKB. The propagation speeds were calculated on both the optical fiber probes and the pressure sensors to approximately $1200 \mathrm{~ms}^{-1}$, which also is according to the sonic speed at the corresponding thermodynamic conditions.

The investigations showed a high reproducibility of the knock onset locations for cycles with $K A>20$ bar. Furthermore the detected knock onset locations for both reference points were always in the end gas. That is a strong dependence between the formation of $\mathrm{KA}>20$ bar and a characteristic propagation of the primary flame front, where the end gas is always located at the operating point specific knock onset locations. If this specific propagation of the primary flame front is according to the mean flame front propagation, or if the detected flame front propagation is according to an extreme cyclic variation should be analyzed by numerical calculations. Also the mean thermodynamic state variables at the knock onset locations will be analyzed within numerical investigations.

\section{NUMERICAL WORK}

Numerical investigations have been carried out to analyze time dependent mean thermodynamic state variables under different time scales. In addition the mean flame front propagation for the assessment of the measured propagation with focus on its cyclic variation was investigated. Therefore the mean heat release, the flow fields, the related distribution of the thermodynamic state variables and further the thermodynamic state variables with their gas dynamic and chemical dependencies were calculated.

\section{$\underline{\text { Heat Release Analysis }}$}

Based on the measured mean pressure curves of the reference points with $\mathrm{CKB}$ and $\mathrm{EKB}$, the heat release and the temperature in the unburned zone were calculated. A two zone model was utilized as well as the lower caloric power reduction because of the under stoichiometric air-fuel ratio. The mean pressure curves are based on 3000 consecutive cycles at DL. Figure 9 presents the mean cylinder pressure for the reference points (top), the calculated heat release (middle) and the calculated end gas temperature (bottom). The times of the knock onsets are also marked in each diagram.

The measured pressure curve of the operating point at $5000 \mathrm{rpm}$ with EKB shows a higher value during the compression (up to $355 \mathrm{CAD}$ ) because of the increased charging efficiency. Due to the longer combustion duration and the retarded ignition the maximum cylinder pressure and thus the pressure at knock onset is shifted towards the expansion stroke, which results in 15 bar lower peak pressure compared to the operating point at $3000 \mathrm{rpm}$. From the heat release (middle) the unburned cylinder fraction at the time of knock onset can be derived. The comparison of the reference points shows, that approximately $15 \%$ remain unburned at the operating point at $3000 \mathrm{rpm}$ with CKB and approximately $38 \%$ at the operating point with $5000 \mathrm{rpm}$ with EKB. The calculated temperature in the end gas (bottom) shows a higher value during the compression for $3000 \mathrm{rpm}$ which is caused by the leaner air-fuel ratio. At time of knock onset the temperature at the operating point with $3000 \mathrm{rpm}$ and CKB is significantly higher (100 K).
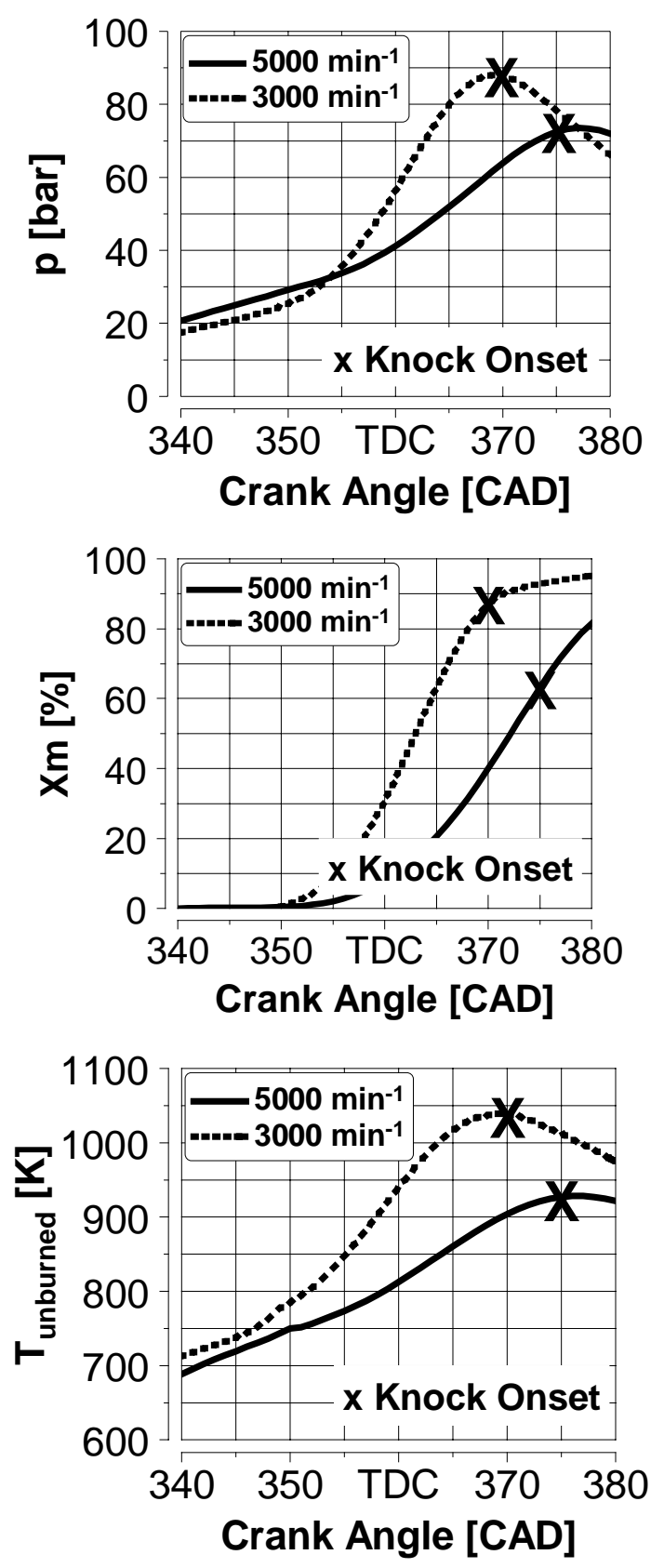

Figure 9: Measured cylinder pressure (top), calculated mass fraction burned (middle) and end gas temperature (bottom).

The calculations showed more critical thermodynamic state variables $(T, p)$ for $3000 \mathrm{rpm}$ with CKB. Whereas the unburned gas fraction seems more critical in the operating point with $5000 \mathrm{rpm}$ and EKB. 


\section{Calculated distribution of state variables}

In the previous sections the investigations to detect the knock onset locations and the primary flame front to determine the end gas areas and the mean thermodynamic state variables in their time dependence are described. In this section the distribution of the thermodynamic state variables should be simulated and their dependency with the detected knock amplitudes be assessed. 3D-flow simulations based on measured pressure curves in the inlet and exhaust ports were performed. The fuel injection in the charge cycle has been considered, while the combustion firstly remain unconsidered. The residual gas of the preceding cycle has also been taken into account.

The temperature distribution represents the primary auto ignition centers for $\mathrm{HCCl}$ combustion [11]. As the autoignition process in $\mathrm{HCCl}$ engines generally is the same as auto-ignition in SI-engines, the temperature distribution at the time of knock onset should be assessed firstly. Figure $\mathbf{1 0}$ shows the detected knock onset locations and the calculated temperature distributions for $3000 \mathrm{rpm}$ with CKB (top) and $5000 \mathrm{rpm}$ with EKB (bottom) at time of knock onset. The temperature distribution is scaled in a range of $30 \mathrm{~K}$ and presented by a horizontal cross section through the cylinder head gasket and 7 further vertical cross section plots between the piston and the combustion chamber roof.

In general, the temperature distributions show significant gradients for both reference points. In case of the operating point with CKB (top) increased temperatures results near the cylinder wall at positions $1-4$ and 8 . The highest temperature can be found between positions 3 and 4 which is the major zone of the detected $\mathrm{KA}>20$ bar. A higher temperature can further be seen at the measured major knock location for $\mathrm{KA}>4$ bar (positions 1 and 2). The lowest temperature is found around the left exhaust valve (positions 5-7), exactly in the area of the most seldom knock onsets. For the operating point with $3000 \mathrm{rpm}$ with CKB the temperature distribution obviously correlates with the knock onsets and the temperature gradient the knock intensity.

The dependency of the temperature distribution and the knock onsets can on first sight also be seen in the reference point with $5000 \mathrm{rpm}$ and EKB (bottom). Exactly in the zone of the detected knock onsets for KA $>4$ bar and $K A>20$ bar the simulations shows a temperature gradient (positions 8 and 1). Although the most seldom knock onsets have been found at positions 4-6, where the highest absolute temperature is located.

The comparison with the experimental determined propagation of the primary flame fronts of both reference points delivers besides the temperature distribution a further constraint for possible knock onset locations. Thus the most seldom knock onset location for the operating point with $3000 \mathrm{rpm}$ and CKB (figure 6) can only be at positions 6 and 7 , because of the existing end gas at position 5 . The determined primary flame front propagation of the reference point with $5000 \mathrm{rpm}$ and EKB (figure 7) firstly reaches the exhaust valves. Therefore, the resulting knock onset locations are primary depending on the flame front and thus only secondly depending on the existing temperature distribution.

This generally leads to the assumption, that the temperature distribution delivers the possible zones for auto ignition. But the occurrence of auto-ignition of these hot-spots then depends on the propagation speed and direction of the primary flame front.
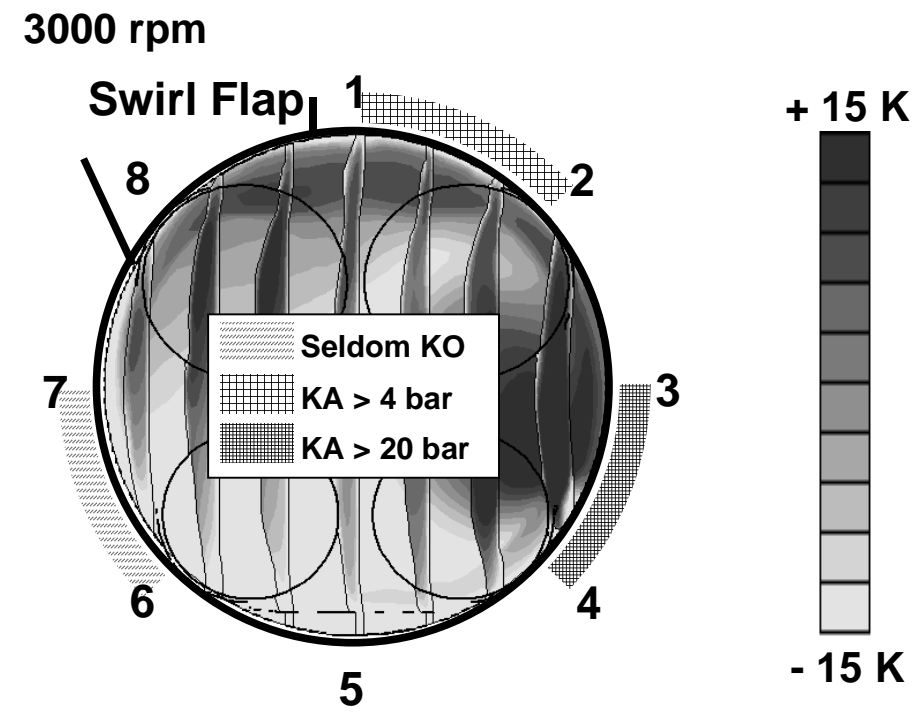

\section{$5000 \mathrm{rpm}$}
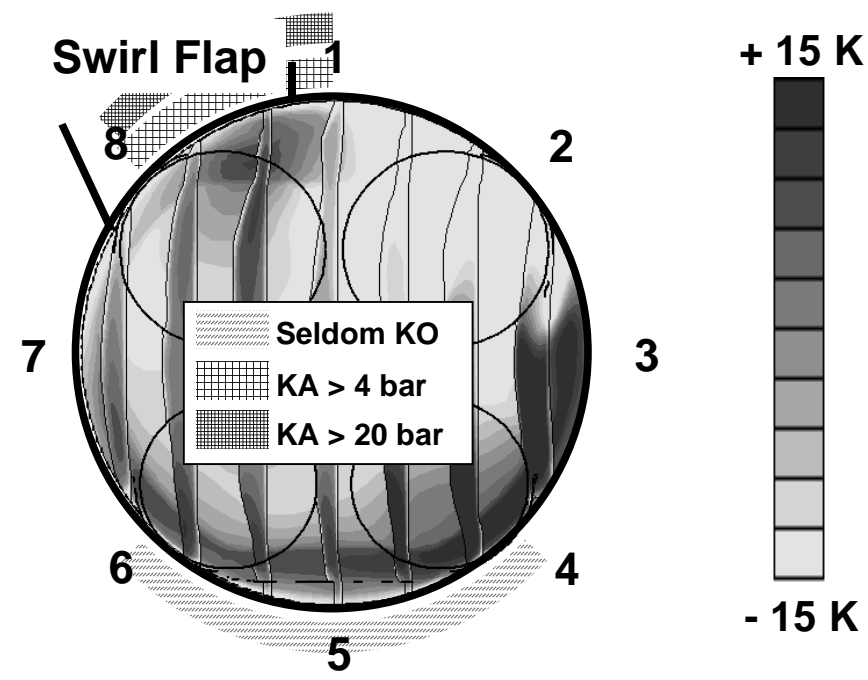

Figure 10: Calculated temperature distribution and measured knock onset locations for $3000 \mathrm{rpm}$ (top) and 5000 rpm (bottom).

The temperature distribution thus contains important information for the operating point specific engine knock behavior. The fuel and residual gas distribution should be analyzed at time of knock onset in their influence in the temperature distribution and with this the engine knock behavior. Figure 11 shows the temperature distributions 
(top) the fuel distribution (middle) and the residual gas distribution (bottom) at time of knock onset for $3000 \mathrm{rpm}$ with CKB (left) and 5000 rpm with EKB (right).
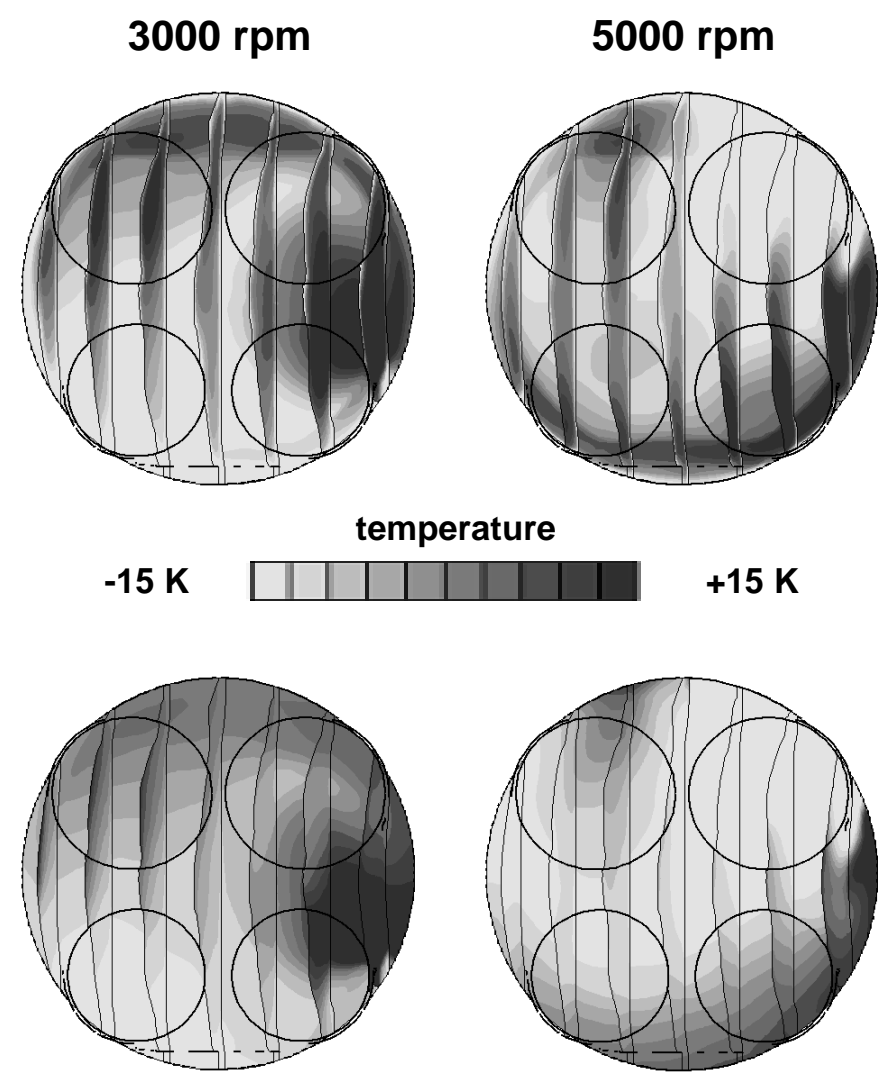

air-fuel ratio $\lambda$

0.7

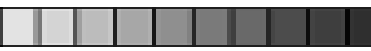

1.3
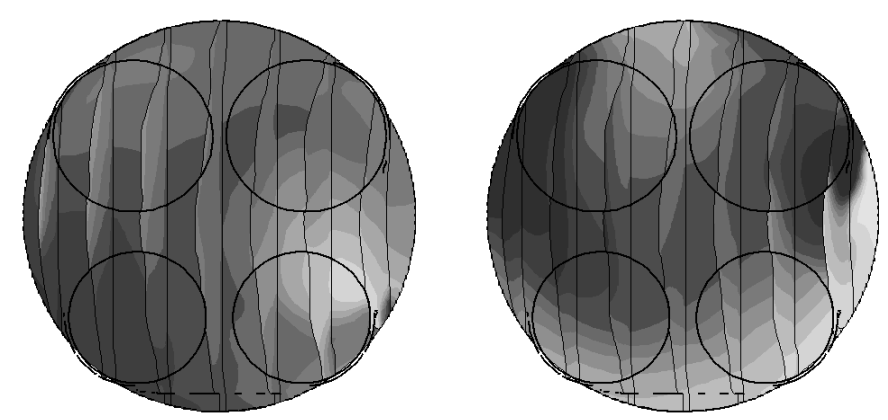

residual gas

$2.0 \%$

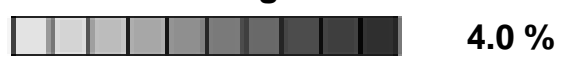

Figure 11: Temperature (top), air-fuel ratio (middle) and residual gas (bottom) distribution for $3000 \mathrm{rpm}$ (left) and 5000 rpm (right).

For both reference points the fuel distribution reflect the temperature distribution, that is rich air-fuel mixture at zones with low temperature and vice versa. Due to the higher heat capacities of fuel, the temperature during the compression remains lower in areas with a rich air-fuel ratio. The hot spot behind the left inlet port at the reference point with $5000 \mathrm{rpm}$ and EKB (positions 8 and 1 , see figure 10) is responsible for the knock behavior, and therefore results from an insufficient mixture formation. If the mixture formation either in general or within the hot spot could be enhanced, the knock behavior, the CR respectively, could be optimized.

The higher temperature level of residual gas in comparison to fresh air-fuel mixture leads to the assumption, that areas with higher amounts of residual gas have a higher temperature level and thus also define hot spots and possible knock onset locations, respectively. But the comparison of the temperature distribution and the residual gas distribution shows the opposite influence of residual gas. The areas with high residual gas fractions show low temperatures and vice versa.

The influence of residual gas highly depends on its concentration and on its temperature respectively. Therefore residual gas is of opposed relevance for the auto ignition in $\mathrm{HCCl}$ combustion and for the auto-ignition of SI-engines with WOT.

Residual gas concentrations higher than $40 \%$ in $\mathrm{HCCl}$ engines result in an increased gas temperature during the compression. Hot spots and auto ignition centers respectively are characterized by higher residual gas fractions. In SI-engines with WOT residual gas fractions below $4 \%$ thus lead to locally lower temperatures during the compression. Together with high residual gas fraction this leads to a decreased probability of knock onset. Like the temperature dependency on the amount of fuel, the residual gas also has an increased heat capacity in comparison to air.

\section{Calculated flame propagation}

Reproducible knock onset locations for KA > 20 bar were found. Based on the measured flame front propagation, the knock onsets were validated in the end gas. The thermodynamic analyses of the end gas areas showed hot spots with slightly enhanced temperatures of about $30 \mathrm{~K}$ at which the auto-ignition starts. With advanced flow simulations including the combustion, the influence of the flame propagation on the temperature distribution in the end gas should be clarified. Furthermore the mean end gas in its position as well as in its size should be compared with the measured end gas regions of cycles with $\mathrm{KA}>20$ bar.

Figure 12 and 13 show the calculated temperature distribution based on the simulated combustion (top) and the measured and the calculated pressure curves (bottom) for $3000 \mathrm{rpm}$ with CKB (figure 12) and 5000 rpm with EKB (figure 13).

The burned zone at time of knock onset is represented by the dark section, the end gas by the light section respectively. The color scale still ranges over $30 \mathrm{~K}$ and the absolute value is adapted to the mean temperature of the end gas. Temperature gradients within the end gas can thus be seen. The border line from light to dark color signalize the flame front at the time of knock onset. 
The comparison of the measured end gas for cycles with $\mathrm{KA}>20$ bar for both reference points (figures 7 and 8 ) and the calculated mean end gas regions are in good agreement. So the measured end gas regions represent no extreme cyclic variation, but rather shows the mean flame propagation of the reference points. Hence, extreme cyclic variations as the reason for different knock behavior can be ruled out.

\section{0 rpm}

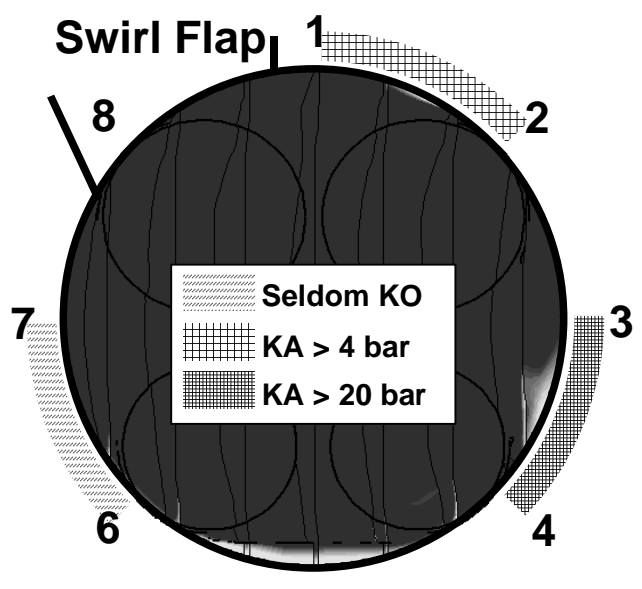

5
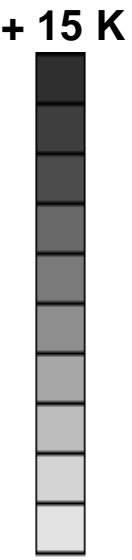

$-15 \mathrm{~K}$

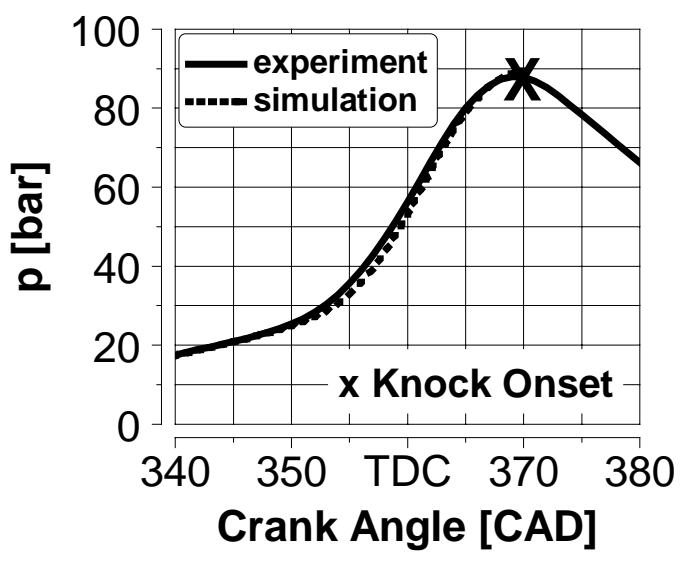

Figure 12: Temperature distribution at time of knock onset based on injection and combustion (top); measured and calculated pressure curves (bottom) for 3000 rpm WOT.

The simulated hot spot behind the left inlet port at $5000 \mathrm{rpm}$ with EKB (figure 10, bottom) at the detected knock onset location for KA > 4 bar and KA $>20$ bar remains unchanged with the simulated combustion. That is decoupled flame front propagation from temperature distribution.

The positions of the detected knock onsets of both reference points result in the calculated end gas, where both end gases show hot spots. The main difference between the operating point specific end gas areas is their volume at the knock onset. At 5000 rpm with EKB the primary flame front has not yet reached the hot spot in the end gas, which leads to a larger hot spot volume at time of knock onset as with $3000 \mathrm{rpm}$ and CKB. Thus the engine specific knock behavior depends not preliminary on the temperature gradients in the end gas and the homogenization of the air-fuel mixture respectively, but on the mean volume of the exothermal center in the end gas at time of the knock onset.

\section{0 rpm}

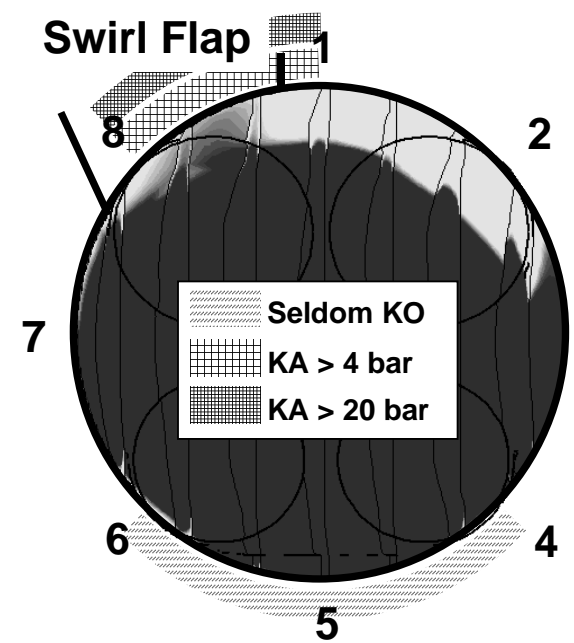

3
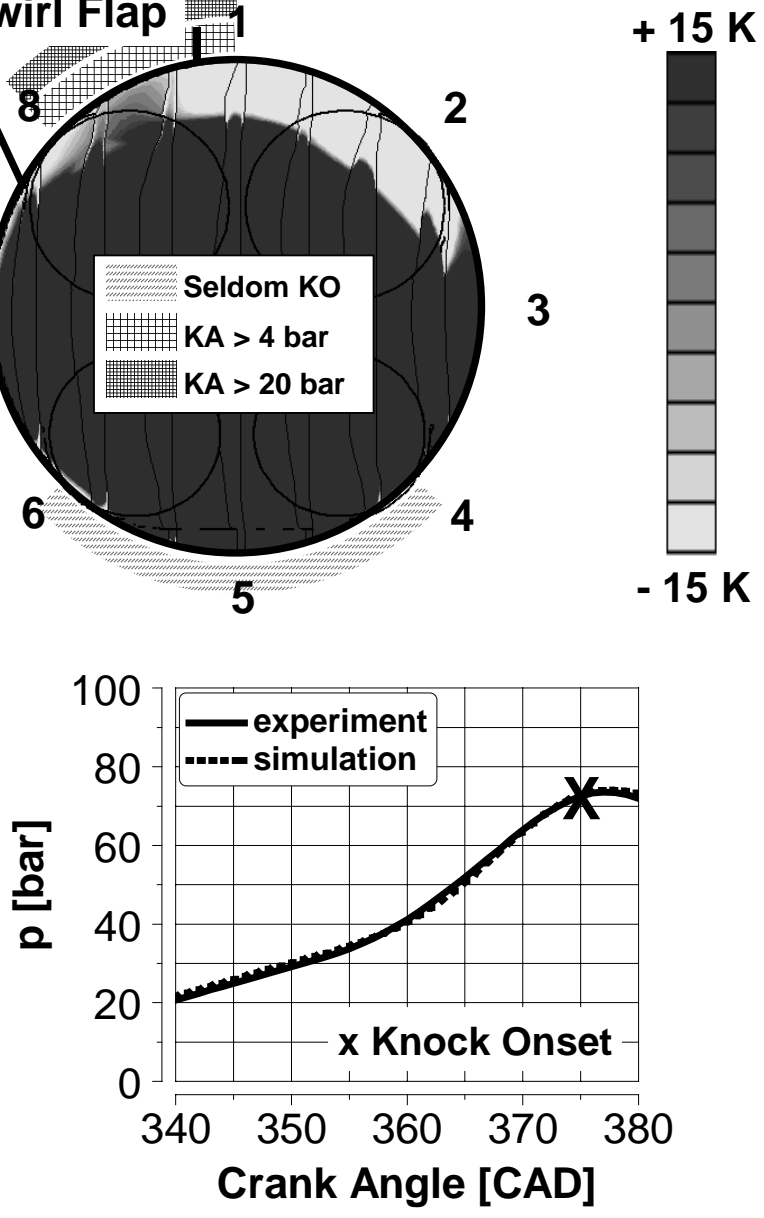

Figure 13: Temperature distribution at time of knock onset based on injection and combustion (top); measured and calculated pressure curves (bottom) for 5000 rpm WOT.

An improved homogenization of the air-fuel mixture at the reference point with $5000 \mathrm{rpm}$ and EKB probably would not improve the knock behavior and CR, since the gradient of the hot spot could be reduced but not be fully eliminated. Furthermore the temperature distribution not only depends on the fuel distribution, but also on the residual gas distribution (figure 11), which can not be influenced directly. A decreased gradient of the hot spot further could result in a worse knock behavior, since flat gradients support the formation of detonations and explosions [1], where finally the complete end gas is converted. Within a variation the engine was operated with port fuel injection, which indeed decreased the gradients significant. Nevertheless the end gas position and end gas volume and subsequently the knock behavior remind unchanged. 
Auto-ignition and knock behavior

The 0D-thermodynamic analysis tool HOMREA allows the calculation of pressure amplitudes, resulting from auto-ignition from so called exothermal centers as calculated in the preceding section. The pressure amplitude resulting from auto-ignition are depending on thermodynamic state variables like temperature, pressure and air-fuel ratio. Another arbitrary parameter is the exothermal volume. Within the succeeding examination the exothermal volume should be calculated based on measured knock amplitudes, which is vice versa the usual approach, where the knock amplitudes are calculated based on exothermal volumes. For the analysis state variables ( $T, p$ and air-fuel ratio) at the time of knock onset next to the measured amplitudes have to be known. Therefore, the initial pressure is taken from experimental data, the temperature from 0D-heat release analysis and the local air-fuel ratio from the flow simulation. The maximal measured knock amplitude of 3000 consecutive cycles for each ignition angle was further used as an input variable for the calculations. Figure 14 shows the dependency between the calculated volume of the exothermal center (VEC) and the measured maximal knock amplitudes (MKA).

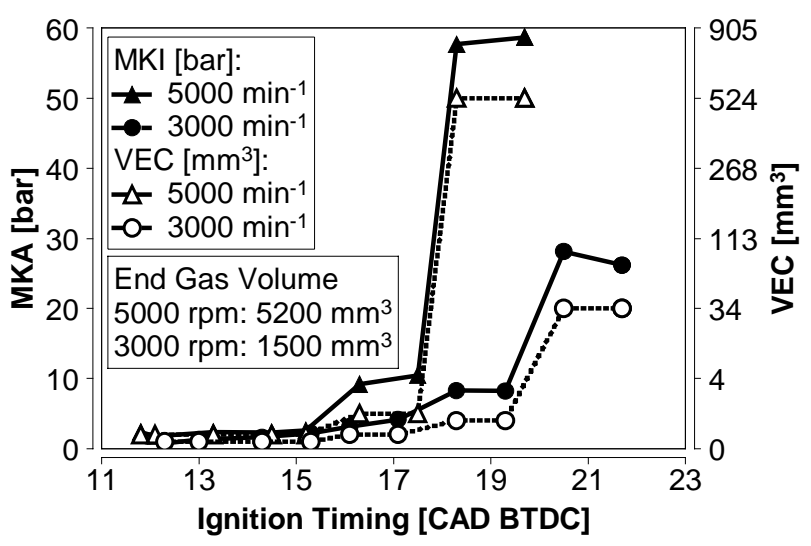

Figure 14: Measured knock amplitudes and calculated volume of the required exothermal center for $3000 \mathrm{rpm}$ and $5000 \mathrm{rpm}$.

At first the volume of the exothermal center increases continuously and at DL abruptly. Pressure amplitude and exothermal volume indicate a linear correlation. The measured knock amplitude of 60 bar in the operating point with $5000 \mathrm{rpm}$ (EKB) thus can be explained with the dynamic and chemical properties of exothermal volumes of about $0.5 \mathrm{~cm}^{3}$. In the operating point with $3000 \mathrm{rpm}$ (CKB) the exothermal volume for the knock amplitude of 30 bar was $0.1 \mathrm{~cm}^{3}$. The exothermal volumes show, that only fractions of the end gas volume (see figure 14) participate at the formation of knock amplitudes. The state variables at $\mathrm{DL}$ at the operating point with CKB (87 bar, $1050 \mathrm{~K}$ ) seems more critical than at the operation point with EKB (75 bar, $850 \mathrm{~K})$. Accordingly the air-fuel ratio and the volume of the exothermal center are the parameters with the strongest influence on pressure amplitudes and on the engine knock behavior.

\section{CONCLUSIONS}

The knock behavior of Sl-engines under full load conditions is of highest importance for the applicability and efficiency of knock control systems. The knock behavior can strongly be affected by the combustion (duration, end gas location and cyclic variations), the incylinder flow field (swirl, tumble) and the mixture formation process (direct injection, port injection) in terms of inhomogeneity and related temperature distribution.

Generally, auto ignition takes place at the hot spots in the end gas region. These hot spots result from different heat capacities of air, fuel and residual gas. Hence, even engines with an ideal mixture formation process can demonstrate undesirable knock behavior. Only in the case that the residual gas and the air-fuel mixture could ideally be homogenized, the limit of knock could be significantly shifted and therewith the thermodynamic efficiency be enhanced.

Because the knock amplitude primary depends on the volume of the hot spot at the time of auto ignition, the knock limit as well as the knock behavior generally can positively be influenced by decreasing this volume. A faster primary flame front propagation or a changed location of the end gas region can thus enhance the knock behavior as well as the knock limit. The propagation of the primary flame front can be influenced by flaps (swirl, tumble) or baffles in the inlet port. Even the knock behavior of a given engine concept can be influenced by the position of the injector and the start and the duration of injection, which influences the in-cylinder flow field, the combustion and the knock behavior respectively, because of the impulse from the injected droplets. Especially injectors with a high mass flow rate and therewith short injection duration offer a wide range of possible start of injection timings with the possibility to improve the knock behavior.

Next to the volume, the air-fuel ratio of the hot spot strongly influences the auto ignition and the knock behavior respectively. The time delay for auto ignition decreases for enriched air-fuel mixtures in the hot spot, which results in earlier times of auto ignition and therewith in possibly increased hot spot volumes with a deterioration of the knock limit. From this point on, the mixture formation process can either be enhanced and the hot spot be eliminated or significantly be declined and the air-fuel ratio of the hot spot be leaned, so that the resulting knock amplitude is reduced because of the slower chemical conversion rate during auto ignition. If the air-fuel ratio of the hot spot in the end gas could be leaned to $\lambda>3$, no pressure wave would be generated.

The cyclic variations of the combustion, of the in-cylinder flow field and of the mixture formation process are further responsible for different knock behaviors. Even if the mean flame front propagation and the mean temperature distribution seems uncritical, cyclic variations can lead to undesirable knock behavior. 


\section{ACKNOWLEDGMENTS}

The authors wish to thank the FVV (Forschungsvereinigung Verbrennungskraftmaschinen e.v.) and the industrial partners involved, for their financial support of the research project as well as for their approval to publish this paper.

The authors would also like to thank the DFG (Deutsche Forschungsgesellschaft) for their financial support of this research work.

The authors further thank the Institute for Technical Thermodynamics (ITT) from the Universitaet Karlsruhe (TH) for providing the software HOMREA and their support for the calculations.

\section{REFERENCES}

1. Y.B. Zeldovic

Regime Classification of an Exothermic Reaction with Nonuniformal Initial Conditions

Combustion and Flame, Volume 39, Pages 211-214, 1980

2. G. König, R.R. Maly, D. Bradly, A.K.C. Lau and C.G.W. Sheppard

Role of Exothermic Centers on Knock Initiation and Knock Damage

SAE Transaction Series, SAE Paper 902136, 1990

3. W. Kleinschmidt

Zur Simulation des Betriebes von Ottomotoren an der Klopfgrenze

VDI-Fortschrittsbericht, Reihe 12 422, VDI 2000

4. R. Worret, S. Bernhardt, F. Schwarz and U. Spicher Application of Different Cylinder Pressure Based Knock Detection Methods in Spark Ignition Engines SAE Technical Paper Series, 2002-01-1668

5. J. Warnatz, U. Maas, R. Dibble

Verbrennung, Physikalisch-Chemische Grundlagen,

Modellierung und Simulation, Experimente,

Schadstoffentstehung

Springer Verlag, 2001

6. U. Maas and J. Warnatz

Detailed Numerical Modeling of $\mathrm{H}_{2}-\mathrm{O}_{2}$ Ignition by Hot

Spots

Progress in Astronautics and Aeronautics, Volume 131,1989

7. U. Maas and J. Warnatz

Ignition Processes in Hydrogen-Oxygen Mixtures

and the Influence of the Uniform Pressure

Assumption

Progress in Astronautics and Aeronautics, Volume 113, 1988

8. G. Goyal, J. Warnatz and U. Maas

Numerical studies of hot spot ignition in $\mathrm{H}_{2}-\mathrm{O}_{2}$ and $\mathrm{CH}_{4}$-air mixtures

$23^{\text {rd }}$ Symposium on Combustion, The Combustion Institute, Pittsburgh PA, S. 1767-1773, 1990
9. B. Lewis and G. von Elbe

Combustion, Flames and Explosions of Gases

Academic Press Inc., Orlando, $3^{\text {rd }}$ Edition, 1987

10. H. P. Kollmeier

Untersuchungen über die Flammenausbreitung bei

klopfender Verbrennung

Dissertation, RWTH Aachen, 1987

11. M. Kaufmann, M. Berckmüller, M. Wetzel, M. Hartmann, M. Schenk, N. Brehm und C. Schwarz Thermodynamische Analyse des ottomotorischen HCCl-DI-Brennverfahrens

Haus der Technik, Volume 53, 2005

12. O. Maiwald

Experimentelle Untersuchungen und mathematische Modellierung von Verbrennungsprozessen in Motoren mit homogener Selbstzündung Dissertation Universität Karlsruhe (TH), ISBN 38325-0933-X, 2005

13. J. Zierep

Theoretische Gasdynamik

G. Braun Verlag, Karlsruhe, 1976

14. H.G. Weller, S. Uslu, A.D. Gosman, R.R. Maly, R. Herweg and B. Heel

Prediction of Combustion in Homogenous-Charge Spark Ignition Engines International Symposium COMODIA, 1994

15. H. Peters, R. Worret and U. Spicher Numerical Analyses of the Combustion Process in a Spark-Ignition Engine $5^{\text {th }}$ International Symposium, COMMODIA 2001, Nagoya, Japan, 2001

\section{DEFINITIONS, ACRONYMS, ABBREVIATIONS}

$\begin{array}{ll}\mathrm{t}_{\mathrm{e}} & {[\mu \mathrm{s}]} \\ \mathrm{CR} & {[\mathrm{CAD}]} \\ \mathrm{KL} & {[\mathrm{CAD}]} \\ \mathrm{DL} & {[\mathrm{CAD}]} \\ \alpha_{\mathrm{i}} & {[\mathrm{CAD}]} \\ \mathrm{CKB} & \\ \mathrm{EKB} & \\ \mathrm{KA} & {[\mathrm{bar}]} \\ \mathrm{T} & {[\mathrm{K}]} \\ \mathrm{T}_{0} & {[\mathrm{~K}]} \\ \mathrm{t} & {[\mathrm{s}]} \\ \mathrm{p} & {[\mathrm{bar}]} \\ \mathrm{p}_{0} & {[\mathrm{bar}]} \\ \overline{\mathrm{C}}_{\mathrm{p}} & {[\mathrm{J} / \mathrm{molK}]} \\ \Re & {\left[\mathrm{J} / \mathrm{mol}^{\mathrm{K}}\right]} \\ \mathrm{R} & {\left[\mathrm{mol} / \mathrm{m}^{3}\right]} \\ \mathrm{c} & {\left[\mathrm{mol} / \mathrm{m}^{3} \mathrm{~s}\right]} \\ \dot{\mathrm{w}}_{\mathrm{i}} & {\left[\mathrm{J} / \mathrm{mol}^{3}\right]} \\ \overline{\mathrm{h}} & {\left[\mathrm{m}^{3}\right]} \\ \mathrm{V} & {\left[\mathrm{mm}^{3}\right]} \\ \mathrm{V}_{0} & {\left[\mathrm{~mol} / \mathrm{m}^{3}\right]} \\ \mathrm{C}_{\mathrm{i}} & \\ \kappa & \\ \tau & {[\mathrm{ms}]} \\ \lambda & \end{array}$

excitation time control range

knock limit damage limit ignition angle controllable knock behavior extreme knock behavior knock amplitude temperature initial temperature time pressure initial pressure molar heat capacity of mixture general gas constant concentration of mixture molar reaction rate molar enthalpy of species $i$

Volume initial Volume concentration of species $i$ isentropic exponent ignition time delay air-fuel ratio 